\title{
La cultura del trabajo como recurso para la cultura del ocio: activación turística de patrimonio minero-industrial en Argentina
}

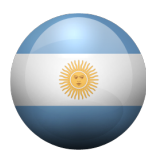

\section{Aldo Ramos Schenck}

Master en Ecoauditorias. Posgrado en Consultoría turistica. Universidad Nacional del Centro de la Província de Buenos Aires - Centro de Investigaciones y Estudios Ambientales. Facultad de Ciencias Humanas. Tandil [Buenos Aires] Argentina. <aldogramos@gmail.com>.

\section{Guilhermina Fernández Zambon}

Master en Gestión Publica del Turismo. Universidad Nacional del Centro de la Província de Buenos Aires Centro de Investigaciones y Estudios Ambientales. Tandil [Buenos Aires] Argentina.

$<$ guillermina_73@hotmail.com>.

\section{Resumen}

El presente trabajo desarrolla el tema del uso de recursos culturales producidos por las actividades minero-industriales y su revalorización para el turismo y la recreación, expresando los tipos de proyectos para poder realizarlo y las problemáticas asociadas. Se plantea un análisis para el caso de Argentina y las potencialidades y dificultades para la activación turístico-recreativa de algunos de los recursos existentes.

\section{Palabras clave}

Recursos culturales; trabajo; minero-industrial; turismo; recreación.

\section{The culture of the workplace as a resource for the leisure culture: tourism activation of heritage industrial-mining in Argentina}

\begin{abstract}
This paper develops the theme of the use of cultural resources produced by the activities mining-industrial and its revaluation for tourism and recreation, expressing the types of projects to be able to perform it and the associated problems. There is an analysis for the case of Argentina and the potentialities and difficulties for tourist-recreation activation of some of the existing resources.
\end{abstract}

\section{Keywords}

Cultural resources; work; industrial-mining; tourism; recreation. 


\section{Introducción}

La cultura como manifestación identitaria de una comunidad o grupo social, a través de elementos materiales o inmateriales que tienen cierta permanencia en el tiempo, se encuentra en permanente evolución a partir de los cambios y transformación que sufre la sociedad. En dicho contexto se encuentran también comprendidas las áreas y estructuras minero-industriales, dentro de las cuales podemos incluir elementos inmuebles como las zonas de producción, de vivienda, etc., objetos muebles como las maquinarias, herramientas, archivos, etc., y podemos agregar los modos de vida de los trabajadores, el know how de los procesos productivos.

Considerando esto, los objetivos del trabajo son a) presentar a las áreas y estructuras mineroindustriales como recursos para organizar productos recreativos, que permitan recuperar espacios industriales abandonados o usar establecimientos industriales en funcionamiento pero que pueden incorporarse a este tipo de emprendimiento de desarrollo turístico y b) realizar un diagnostico de los recursos mineros e industriales de Argentina para considerar su potencialidad para el desarrollo de actividades turístico-recreativas.

Estos proyectos pueden ser inscriptos dentro de la recreación en general y del turismo cultural en particular. La creación de diferentes productos recreativos puede permitir la reactivación de las economías locales por constituirse, en definitiva, en una nueva actividad económica, que no necesita de grandes inversiones sino que es preciso fundamentalmente pensar como constituirlos en recursos atractivos para el turista. Lógicamente esto requiere de una organización, donde compartan responsabilidades tanto el sector público como el privado, pero siempre propiciando el mayor grado de participación social.

En definitiva, a través de las rutas turísticas, centros de interpretación, ecomuseos, etc., es posible propiciar un desarrollo local sustentable, permitiendo así que ciertos espacios periféricos se integren a la economía.

\section{Las actividades turístico-recreativas culturales en el siglo XXI}

Las actividades turísticos-recreativas de tipo cultural han experimentado en las últimas décadas un crecimiento y dinamismo extraordinarios, lo que implica necesariamente la búsqueda constante de nuevos productos.

Después de la segunda guerra mundial el turismo de masas se afianzó en el mundo, pero hacia la década de 1980, comienza a generarse en el mundo una conciencia de tipo ecologista, de respeto hacia el ambiente y las culturas. Este fenómeno, relativamente reciente, implica que la cultura dejo de ser un placer de un grupo reducido para pasar a convertirse en una exigencia de un porcentaje importante de la población mundial.

Actualmente, las motivaciones para el uso del tiempo libre, además de las tradicionales que no han desaparecido, responden fundamentalmente a cuestiones relacionadas con el conocimiento, la identidad y la diversión. Son personas activas que demandan actividades y experiencias en los destinos, que les permitan estar en mayor contacto con la población y el espacio local. Por esta razón, la demanda de productos turístico-recreativos relacionados con la cultura o con procesos que hacen a la identidad de los pueblos, se ha ido configurando como uno de los componentes con mayor proyección del sector turístico y recreativo en las últimas décadas.

Estos cambios promueven toda una serie de motivaciones relacionadas a la cultura y propician el conocimiento y la diversión usando como recursos, por ejemplo murallas, calles, castillos, plazas, palacios, iglesias, museos, antiguas industrias, etc., así como otras manifestaciones como son: fiestas y gastronomía típicas, folklore o representaciones culturales contemporáneas: conciertos, exposiciones de arte, etc.

Como explica Maribel Rodríguez Achutegui (2002), "el hombre contemporáneo ha hecho del 
consumo cultural una práctica generalizada dentro de sus hábitos de ocio y tiempo libre. Con esta práctica busca no sólo encontrar explicación a los fenómenos en sí, sino que pretende encontrarse a sí mismo, definirse como persona buscando referentes culturales propios o a través del contacto con otras realidades distintas". En cuanto a los intereses desde una perspectiva cultural, la misma autora reconoce la existencia de tres tipos fundamentales:

1. Histórico-nostálgico. Se trata del gusto, un tanto romántico, de lo antiguo. Pueden disfrutar con ruinas, solamente por sus valores estéticos y simbólicos. No necesitan prácticamente ningún tipo de explicación o comunicación para salir satisfechos.

2. Mecánico-moderno. En este caso se trata del disfrute que se alcanza a través del conocimiento de los mecanismos que rodean al elemento cultural. Son aquellas personas que para salir satisfechos de una visita deben conocer el quién, cómo, cuando y fundamentalmente el porqué de las cosas. Están por tanto especialmente interesados en los procesos que llevan a que algo sea tal y como lo ve. Serán por tanto los que disfruten comprendiendo y viendo el funcionamiento de un molino, o los distintos sistemas de producción de una industria.

3. Eco-deportista. Se trata del interés y motivación especial hacia el medioambiente, paisajes, formas de vidas tradicionales, etc., lo que se une con el gusto por deportes de bajo impacto. Son aquellos que disfrutan haciendo senderismo, alpinismo, etc.

\section{Revalorizando la cultura del trabajo a través de actividades turístico-recreativas en áreas minero-industriales}

Considerando específicamente a las áreas y estructuras minero-industriales, podemos incluir los objetos inmuebles, (zonas de producción, de vivienda, etc.), los muebles (maquinaria, herramienta, los archivos, etc.) y a esto pueden agregarse los modos de vida de los trabajadores, el know how de los procesos productivos, asociados a la industria y a la minería como un verdadero sistema.

Estos espacios como recursos culturales han permitido la creación de productos recreativos y turísticos, valorados en el mercado, desde el punto de vista arquitectónico, museístico y recreativo.

En Estados Unidos, desde finales de los años '70, existen iniciativas para valorizar algunas instalaciones industriales. Entre las más tempranas se encuentra la puesta en valor del núcleo manufacturero textil de Lowell, en Massachussets (1977), al que siguieron otras acciones diversas; como las fundiciones de Birmingham en Alabama. En Europa, posiblemente interesados por las realizaciones norteamericanas, se comienzan a generar también proyectos en esta área. Y pese a no ser pioneros, como expresan Ibáñez y Zabala (2003), la iniciativa de recuperación de espacio o área industrial con mayor reconocimiento internacional es el Ironbridge Gorge Museum, ubicado en el valle del río Severn, región que fue el principal centro productor de hierro de Gran Bretaña. En 1959, los propietarios de la fundición de Coalbroodale descubrieron el horno donde Abraham Darby utilizó por primera vez, en 1709, coque para fundir el hierro. Junto a este horno crearon un pequeño museo donde expusieron una muestra de los productos elaborados por dicha fundición. En 1968 la recién creada Fundación del Museo del Valle de Ironbridge se hizo cargo de este proyecto de difusión cultural, proponiéndose la recuperación del patrimonio industrial del valle, preservando el emplazamiento y las técnicas de producción. Comenzaron restaurando el viejo puente de hierro de fines del s. XVIII (The Ironbridge) y en 1979 se inauguró el museo del hierro. Poco tiempo después, se concretó el proyecto de ecomuseo de Blits Hill, en torno a la reconstrucción de un pueblo típico de la época victoriana, con sus pozos de hulla, forjas y ladrillares. También se transformaron en museos la fábrica de cerámica de Jackfield y la de porcelana de Coalport. Además, se restauraron dos caserones de la familia Darby y varias viviendas obreras. Hoy en día recibe más de 300.000 visitantes al año, generando unos ingresos de aproximadamente 50 millones dólares. (PUCHE, 1996). Por otra parte Alemania, desde mediados de los años '80, ha promovido la conservación de cuatro grupos de hornos altos del siglo XX: ejemplares aislados de Nuenkirchen y Hatigen y las plantas siderúrgicas de Duisburg-Meiderich y Völklingen. Este último fue el mayor emporio manufacturero de perfiles metálicos de Alemania y tras su cierre en 1986 se han conservado todos los elementos del sistema productivo (6 hornos altos, 10 estufas, el sistema de transporte para la carga de los hornos, la planta de purificación y tratamiento de gas, depósitos de carbón, 4 baterías de 
coque, etc.), lo cual a partir de la promoción turística lo ha convertido en una importante fuente de beneficios económicos. Incluso la importancia de este sitio implicó, que en diciembre de 1994, la UNESCO lo proclamara Patrimonio de la Humanidad.

Otro país del viejo continente que ha generado proyectos en este sentido es Escocia, donde, por ejemplo, se han valorado las antiguas industrias del hierro en Dunaskin y Ayrshire, investigando la promoción de la herencia industrial regional para el desarrollo económico.

Ahora bien, el desarrollo de actividades turístico-recreativas a partir de estos recursos culturales no debe quedar reducido a sectores industriales, abandonados o antiguos. A partir de los casos mencionados y de otros muchos, podemos afirmar que en los últimos años han aumentado considerablemente, tanto por parte de la iniciativa privada como pública, el interés por la creación de productos recreativos y turísticos relacionados a los recursos culturales heredados de la actividad minero-industrial, lo que se ha traducido en un aumento de los proyectos para preservar y valorizar estas áreas, teniendo como uno de sus objetivos prioritarios el de ser una fuente de ingresos de las áreas deprimidas por causa del fin de una determinada actividad económica predominante.

Aunque cabe aclarar que muchas de estas experiencias se han asociado a proyectos de tipo educativo, no puede negarse el atractivo potencial de las instalaciones industriales y mineras para el desarrollo de actividades turísticas y recreativas. Allí se pueden incorporar distintos procesos históricos de desarrollo, de evolución de las formas laborales, de cambios socioeconómicos presentes en determinada sociedad, por efectos de la urbanización fabril y/o de la incorporación de nuevas tecnologías.

Las áreas minero-industriales constituyen una oferta competitiva importante y original, respecto de otras de carácter tradicional, o complementaria, contribuyendo a aumentar los atractivos turísticorecreativos regionales, generando un movimiento en torno al desarrollo económico local.

Procesos que articulan maquinarias, hornos, plantas extractivas del pasado y del presente y sus respectivas unidades habitacionales. Elementos que sin ninguna duda transformaron a los actores sociales, su cultura y el territorio mismo y que tienen un potencial para ser rehabilitados y convertidos en atractivos turísticos o recreativos, involucrando a la comunidad local.

Así, algunos de estos proyectos se pueden incluir dentro de los movimientos de dinamización territorial que en las últimas décadas proponen que es posible observar que los recursos del turismo, el ocio, la promoción cultural, natural y de cualquier tipo de atractivo con un cierto interés, integran una potencial estrategia de futuro en algunas áreas del interior. De esta forma [...]

[...] se contemplan estos recursos como una alternativa para un nuevo modelo de desarrollo local que ayude a superar un periodo de recesión económica, demográfica y social, consecuencia de la desaparición o el declive irreversible de las actividades productivas tradicionales, y de su no-sustitución por otras en breve (LLURDES i COIT, 1995).

Incluso se apuesta a la integración entre diferentes unidades socioterritoriales funcionales a un sistema mucho más competitivo o dinámico que puede ofrecer sinergias positivas. Estos cambios se han visto favorecidos por transformaciones dentro del tiempo libre en general y del turismo en particular, tanto en la modificación del perfil del turista, por efectos del incremento de los niveles culturales, educativos y las mejores condiciones de vida; como cambios en las formas de concebir el tiempo libre, de revalorizar otros lugares, menos masificados y especiales, del agotamiento de destinos y productos tradicionales, etc. Esto ha significado que en la competencia para atraer este nuevo tipo de actividades alternativas se diseñen propuestas nuevas e imaginativas, en sitios no tradicionales y con valor histórico-cultural singular.

De esta forma algunos países, caracterizados por poseer y generar un turismo tradicional, intentan atraer a este nuevo tipo de turista interesado en otras alternativas, debiendo establecer otros medios de gestión dirigidos al mantenimiento y en algunos casos a la restauración de antiguas estructuras, como los complejos fabriles. 
Para los países en vías de desarrollo implementar alguna de estas alternativas ha sido problemático, especialmente en el caso de las infraestructuras e instalaciones, puesto que es restringido el acceso a recursos económicos destinados a este tipo de actividades y también reducida o inexistente la jurisprudencia referida al resguardo de este tipo de recursos. Pero por otro lado América Latina ha sido objeto de la elección de muchos flujos de turistas internacionales que han elegido sus manifestaciones culturales como elementos alternativos y en tal proceso pueden incluirse nuevos productos relacionadas a las áreas y estructuras minero-industriales.

Dicha reactivación es fundamental, si se tienen en cuenta los potenciales peligros de destrucción, por falta de recursos, de vestigios industriales y mineros del siglo XIX y XX, tanto los que ya están abandonados como aquellos que se enfrentan actualmente a la dinámica de procesos de reconversión productiva y caída en los niveles de rentabilidad. En dicho contexto, la experiencia indica que no solo el visitante debe ser motivado a vivir estas experiencias, sino también puede y debe involucrarse a la propia comunidad a través de actividades recreativas, que los lleven a vincularse con la gestión de estos recursos, que en definitiva le pertenecen, como herencia.

Así la creación de productos recreativos puede convertirse en un motor de desarrollo en áreas económicamente deprimidas, aunque deben adecuarse las instalaciones inactivas, tanto desde el punto de vista ingenieril como urbanístico, con una nueva funcionalidad didáctica y cultural.

Pero la implementación de una propuesta de estas características no se produce sin obstáculos. Se necesita desde luego una buena disposición de las empresas y entidades municipales, provinciales y nacionales, cuestión esta que presenta en la mayoría de los casos situaciones conflictivas y puja de intereses que pueden hacer fracasar las gestiones. Por ejemplo, la visita a establecimientos que están en actividad, podría ocasionar problemas y molestias en los procesos de producción o en ocasiones las instalaciones suelen no estar preparadas para ser recorridas por visitantes. Por otro lado, y desde un punto de vista económico, la puesta en valor además de generar empleos directos e indirectos, mantiene una dinámica productiva que permite el mantenimiento edilicio de las plantas, así como el fortalecimiento de la imagen de la empresa en ciertos sectores.

Esto, revisado en un contexto mayor, puede significar la recuperación de espacios abandonados por la industria y la minería, incluso a partir del cambio del uso del espacio y su resignificación, permitiendo mediante la actividad recreativa, plantear la recuperación de áreas donde la pérdida de actividades productivas por agotamiento de los recursos naturales en algunos casos o por efectos de políticas económicas globales desde la década de 1980 y 1990, han dejado de proveer recursos, dando origen a la conformación de pueblos fantasmas. Manifestación de infraestructuras y construcciones representadas por unidades habitacionales o comunidades de fábrica, pueblos completos marginados, que luego del abandono de unidades productivas como los antiguos hornos caleros de las primeras décadas del siglo $\mathrm{XX}$, no encuentran un camino a seguir o una estrategia en conjunto que permita escapar a la alternativa de emigrar, dejando parte de su historia. Así, desde estas construcciones manifestadas como una pesada herencia, de aparente escaso valor, se puede proyectar un nuevo tipo de desarrollo que revalorice las viejas estructuras ofreciendo un nuevo producto.

Con el pasado industrial, es posible realizar emprendimientos cuyos objetivos deben ser culturales, haciendo accesible al público un patrimonio industrial de enorme potencial, sensibilizando a los visitantes con la diversidad y riqueza de la actividad industrial y los problemas medioambientales que las empresas extractivas han generado.

También educativos, dirigidos sobre todo a los niveles primarios y secundarios, despertando el interés de los jóvenes por las múltiples facetas de la ciencia, la tecnología y los procesos de cambio que dieron como resultado un sistema industrial y minero de enorme capacidad productiva" (PAZ y VISVEQUI, 2001). Por lo tanto el desafío no es meramente un problema del responsable de la planta industrial o de la explotación minera, es una problemática social que va desde la propia concepción de un bien patrimonial para la comunidad, hasta su gestión y puesta en valor y la participación de diferentes sectores que ocupan ese territorio. 
$\mathrm{Al}$ respecto es necesario considerar que no solo es importante recuperar las áreas y estructuras de la actividad minero-industrial, también es fundamental incluirlo en el espacio, porque como expresa Jacques Lecours (1999) [...]

[...] si el territorio es el soporte fundamental de la industrialización, hay que comprender al territorio para comprender la industrialización. En la interpretación y la puesta en valor del patrimonio industrial se debe tener en cuenta a su vez, el contexto espacial y temporal más amplio posible, intentando mostrar, luego el contexto global donde han funcionado y funcionan distintas empresas. El sistema industrial es transformador no solo de productos sino de las sociedades que se han involucrado con el, y que desde esa posición han tejido redes sociales (LECOURS, 1999).

Pero, pese a considerar a estos espacios como un importante recurso turístico y recreativo, es necesario considerar que existen situaciones o factores que impiden en ocasiones activar a los bienes mineros e industriales. En tal sentido Dietrich Soyez (CAPEL, 1996) señala que las principales barreras que se presentan son:

1. Cognitivas: como la idea de que la industria no es un bien cultural, no tiene valores estéticos, no es interesante, o que la visita a ese tipo de instalaciones no es elegante.

2. Económicas: los dueños de las instalaciones obsoletas pueden pensar que es más rentable vender la maquinaria como chatarra, o enajenar el terreno, o dedicar el edificio a otras ocupaciones; hay también dificultades para el cambio de funciones, y es elevado el coste de la restauración.

3. Legales o administrativas: derivadas de las competencias poco claras sobre las actuaciones a realizar; o físicas, relacionadas con la lejanía de algunas instalaciones respecto a las rutas turísticas tradicionales, e incluso con relación a potenciales accidentes.

Algunas o todas estas barreras están presentes en muchos casos en los países de América Latina, por lo que aún el desarrollo de actividades recreativas relacionadas con la historia y la actividad industrial son escasas y de tratamiento muy reciente, más aún cuando se trata de su puesta en práctica.

\section{Tipos de proyectos turístico-recreativos}

Como fue expresado, las áreas y estructuras minero-industriales, como bienes culturales son recursos sociales y económicos y los restos físicos de ese pasado o los establecimientos que se encuentran en funcionamiento, son potencialmente recursos para el desarrollo de actividades recreativas.

La puesta en valor del recurso histórico encerrado en la industria y minería, puede ser una herramienta de desarrollo local y los proyectos de reutilización pueden constituir un eje estratégico de crecimiento regional.

La activación recreativa y turística de las estructuras y áreas minero-industriales puede realizarse de diferentes formas, la mayoría de las cuales están inscriptas dentro de proyectos de gestión cultural. Los proyectos de uso pueden plasmarse a través de rutas turísticas, circuitos urbanos y/o periurbanos, centros de interpretación, museos al aire libre, ecomuseos, etc.

Considerando el aprovechamiento que puede realizarse del recurso minero-industrial, este se produce básicamente en los siguientes cinco grandes sectores:

4. Área de extracción: a cielo abierto, subterránea e instalaciones de apoyo.

5. Área de tratamiento del material: depósitos, lavado, clasificación y

6. Transporte: fluvial y marítimo o terrestre.

7. Uso social y administrativo: viviendas de los trabajadores, equipamientos, oficinas, etc.

8. Zonas industriales: estructuras, maquinarias pesadas y livianas, etc.

\section{Factores a considerar en proyectos de turismo minero-industrial}

Es necesario definir ciertas estrategias a seguir, tanto por parte de los gobiernos, como del sector privado y la comunidad. El sector público debe crear las condiciones para favorecer la participación social de todos actores involucrados, por ejemplo a través de un marco normativo, estímulos fiscales, etc. 
Los ciudadanos y el sector empresarial deben participan en la propia recuperación de las áreas industriales y mineras abandonadas dentro del paisaje urbano o en el medio rural o en la utilización de establecimientos que están funcionando y de esta forma pueden aumentar sus ingresos.

Así, es necesario involucrar al gobierno nacional, provincial, municipal, con las comunidades locales y los propietarios de los inmuebles para recuperar las áreas y estructuras minero-industriales y reutilizarlas con fines recreativos y turísticos.

A la par de esa búsqueda de articulación de los distintos sectores, es fundamental realizar un estudio sistemático de los recursos industriales y mineros para evaluar particularidades, diversidad y potencial como recurso recreativo-turístico. En este punto existen numerosos trabajos desde distintas disciplinas como la arquitectura, antropología, diseño industrial, historia, etc., pero, en muchos casos, sin relación entre ellos, ni con la actividad turística en la mayoría de los casos.

La revalorización de estos espacios requiere de un trabajo interdisciplinario, con objetivos comunes. En este caso vinculados al valor turístico de ese elemento y de su integración con otros elementos y con un mercado potencial. En las últimas tres décadas, la arqueología industrial, ha realizado importantes aportes, explicando a la industria en su contexto social y la importancia de la revitalización de las viejas y nuevas arquitecturas industriales. Pero el inventario a realizar implica considerar todo el conjunto de elementos preindustriales e industriales, así como las obras públicas, vinculados al desarrollo industrial, es decir, todos aquellos testimonios del trabajo industrial y un análisis y caracterización de procesos productivos, de capacidades técnicas, formas de organización del trabajo y los entornos espaciales asociados.

El problema de la falta de estudios es grave porque la conservación de las áreas y estructuras minero-industriales por el hecho de constituir la identidad de una comunidad no es suficiente y en ocasiones es necesario presentar un plan de preservación y conservación que incluya algún tipo de uso, el cual debe implicar un ingreso económico, tanto de forma directa como indirecta.

De esta manera se pretende un desarrollo integral que haga productiva la inversión en la recuperación de los recursos, impulsando la economía local y garantizando un desarrollo sustentable. Así, la adecuada conformación y promoción de productos temáticos de la actividad industrial y minera podrían posibilitar la activación de recursos económicos, la creación de empleo y el conocimiento, por parte de turistas y visitantes, de formas de vida y trabajo que representan diversas identidades.

Por otro lado este tipo de programa de desarrollo permitiría recuperar y conservar la herencia de estas actividades con el fin de mantener y/o reconstruir la memoria e identidad colectiva de cada localidad, por ser los establecimientos industriales y las áreas mineras el escenario de la formación de una identidad y cultura del trabajo minero-industrial.

Los productos recreativos basados en recursos relacionados a la actividad minero-industrial pueden:

- Diversificar y mejorar la oferta turístico-recreativa.

- Aumentar la calidad de los productos ofrecidos.

- Colaborar en la adecuación de la oferta a la demanda existente, logando así una diferenciación competitiva.

- Propiciar la desestacionalización de la demanda.

- Fortalecer e integrar los productos a la estructura empresarial, principalmente PyMEs.

- Mejorar la información y señalización turística y hacer uso de la interpretación, como una herramienta para acercar de una forma atractiva los recursos culturales a los visitantes.

\section{Activación turística de recursos minero-industriales en Argentina}

Como fue expresado el territorio argentino presenta un patrimonio minero e industrial que podemos considerar importante, pese a estar en un país con una base productiva fuertemente basada en un 
modelo agroexportador con nulo o reducido valor agregado. De todas formas existen recursos que pueden ser aprovechado a partir del turismo. Sumado a esto, tenemos las acciones públicas que el gobierno ha encarado tímidamente.

\subsection{Provincia de Jujuy}

Por las Quebradas de Humahuaca, viejas minas precolombianas volverán a sentir el trajín del hombre.

Las explotaciones que se mencionan a continuación se encuentran promocionadas por la provincia como un circuito geológico-minero, aunque algunas de ellas están activas y solo pueden observarse las actividades a determinada distancia.

- Mina Aguilar. La mina El Aguilar, en Abra Pampa en la puna jujeña, a 4.000 metros de altura, además de ser la más antigua de Jujuy, es la única que permanece activa, produciendo plata, zinc y plomo. El yacimiento está en la sierra El Aguilar, habitada por cóndores.

- La Rinconada. Pequeño pueblo atravesado por dos vetas auríferas, y la mina de socavón que conserva intacto el túnel que cavaron los españoles. Cerca está la Laguna Pozuelos, rodeada de una altiplanicie de pastos ralos, hábitat permanente de patos, guayatas, teros y flamencos rosados declarado por la UNESCO Patrimonio de la Humanidad. Cercano a la mina se encuentra el pueblo de Cusi-Cusi con 300 habitantes, donde además del poblado construido en piedra, pueden observarse cultivos de papa y rebaños de ovejas, ejemplos de la forma de vida de siglos atrás.

- Mina 9 de Octubre. La mina, en Puesto Viejo, cercana a la ciudad de San Salvador de Jujuy, fue la primera que proveyó de hierro a Altos Hornos Zapla, el establecimiento siderúrgico ahora privatizado.

\subsection{Provincia de San Luis}

La actividad del hombre en este territorio data de la época precolombina donde los asentamientos indígenas de los Comenchingones, Huarpes,
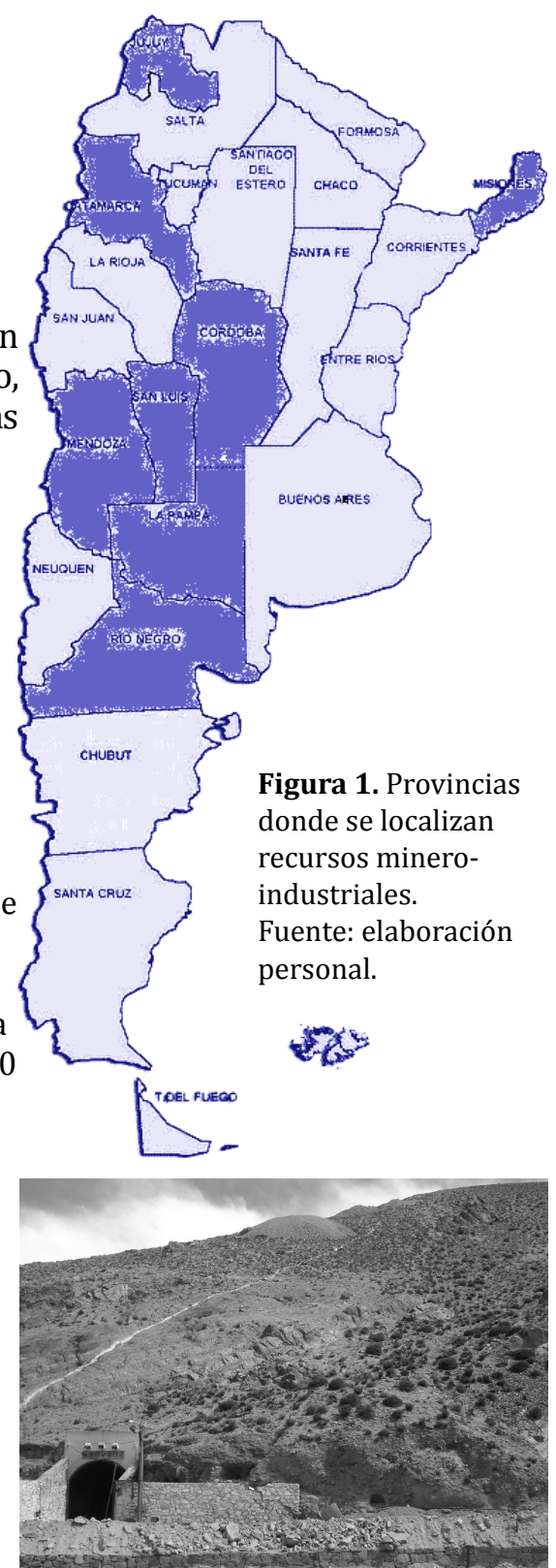

Figura 2. Mina en Jujuy abandonada. Foto: archivo personal. Michilingues y Olangastas desarrollaron la minería, la alfarería y el cultivo en forma primitiva. Son los principales exponentes de esa época, que fueron siendo desplazados por la colonización que trajo consigo la fundación de la ciudad de San Luis en 1594 con el nombre de "San Luis de Loyola de la Nueva Medina de Río Seco".

- Minas El Rincón. Se encuentran a unos $100 \mathrm{Km}$. de la capital de la provincia (Ciudad de San Luis). Ocupan una superficie de 30 × 60 mts, conservándose aún cuatro taperas de piedra que servía de alojamiento para el personal. Existen siete túneles abiertos realizados verticalmente y tres túneles cerrados. Si bien se extraía oro, también puede observarse granito y hierro.

- Canteras El Rincón. Se encuentran en el extremo norte de las Sierras de Socoscora. Estas canteras de cuarzo eran muy importantes para la fabricación de vidrios y el feldespato era empleado para la industria de la loza y sanitarios.

- Minas de Litio. Subiendo una cuesta se llega a la Géminis, como alguna vez se llamó esta mina

RAMOS SCHENCK, A.; FERNÁNDEZ ZAMBON, G.. La cultura del trabajo como recurso para la cultura del ocio: 
hoy abandonada de la cual se extraía litio y en menor cantidad otros minerales tales como: tantalio, berilo, scheelita (mineral formado por tungsteno y calcio), wolframio y cuarzo. Consiste en una serie de socavones realizados por la mano del hombre, con métodos rústicos, ya que las condiciones del terreno impedían llevar maquinarias. En esta mina es posible observar importantes acumulaciones de cuarzo y restos de litio, y una cabaña de piedra que servia de refugio a los mineros.

- Mina El Pilón. Se trata de una antigua mina de oro y esta compuesta de una serie de túneles dispersos entre las lomas, el lugar se semiárido, con predominio de arbustos espinosos.

- Mina La Carolina. Localizada a unos $80 \mathrm{~km}$ de la capital provincial, tras recorrer el valle de Pancanta hasta el pie del cerro Tomolasta, de 2.018 metros sobre el nivel del mar, se llega al poblado, que parece estar ajeno al paso del tiempo. Data de 1792, año en que fue fundada por el entonces Marqués de Sobremonte, en honor a la esposa de Carlos III de España. Este antiguo poblado tuvo su auge a mediados del siglo XIX, cuando un casual descubrimiento generó una fiebre del oro. Muy pronto, la incipiente actividad minera generó que compañías inglesas y españolas llegaran hasta la región para extraer el oro dejando de lado las actividades

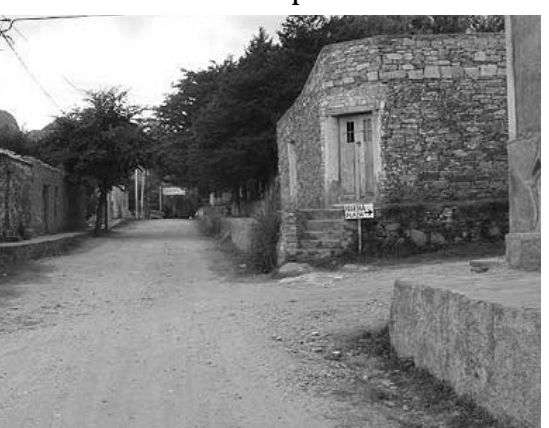

Figura 3. Vista del poblado de La

Carolina. Foto archivo personal. ganaderas de la región. Comenzaron a construirse viviendas de piedra junto a calles angostas que culminaban en oscuros túneles, donde los mineros buscaban el preciado mineral. La actividad turística actualmente consiste en visitar los antiguos socavones, cuya extensión llega a los 300 metros, logrando así apreciar distintos minerales de la corteza terrestre, formaciones de estalactitas, estalagmitas y fallas geológicas.

\subsection{Provincia de Misiones}

- Minas de Wanda y Santa Catalina. La Compañía Minera Wanda S.R.L. comienza sus actividades en el año 1994, adquiriendo el yacimiento denominado Selva Irupé (descubierto en el año 1976) conformando así el primer yacimiento de piedras semipreciosas de la Provincia de Misiones. Los yacimientos se encuentran a 40 kilómetros al sur de Puerto Iguazú, donde la historia geológica aflora en la forma de ágatas, jaspes y amatistas. Las geodas de Santa Catalina y Wanda son piedras volcánicas que, se estima, tienen unos 150 millones de años: todo comenzó con la erupción de un volcán en el actual estado bra-

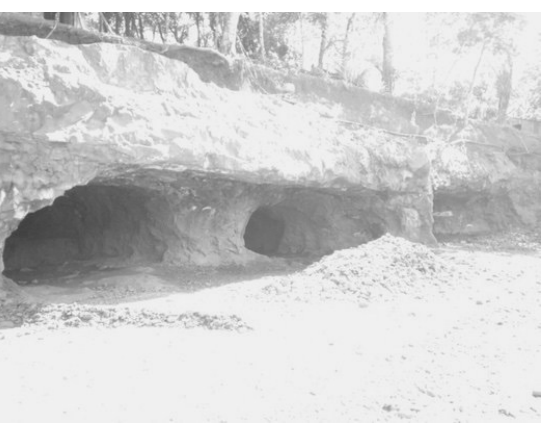

Figura 4. Vista del ingreso a las minas de Wanda. Foto: archivo personal. sileño de Minas Gerais, que llegó hasta Misiones y fue atrapando, a medida que la lava se solidificaba, burbujas de aire y agua capaces de provocar la formación de los cristales de roca, amatistas, topacios, ágatas y jaspes. En otro sector de la mina se ven las maquinarias utilizadas y dinamita casera fabricada a fuerza de salitre, azufre y carbón vegetal, para remover el basalto y sacar a la luz las piedras semipreciosas.

\subsection{Provincia de Catamarca}

- Capillitas. Es el centro de la explotación de la rodocrosita, en el corazón de un yacimiento minero donde se encuentra cobre, plomo, zinc, oro y plata, entre otros minerales. La rodocrosita fue descubierta en 1870 por el geólogo alemán Alfredo Stelzner, recibiendo el nombre de dialoguita o espato frambuesa; posteriormente el alemán Franz Mansfeld la rebautizó como rosa del Inca y llevó incluso muestras al Museo Británico en Londres. El establecimiento Minero Capillitas cerró en 1987 por falta de roca para extraer, pero la explotación prosiguió en manos de pobladores locales que hacia 1992 encontraron nuevamente la veta de la rosa del Inca. Posteriormente se construyo el Refugio del Minero 
y desde allí se recorren los túneles de la antigua explotación donde funciona el museo mineralógico Samuel Reinoso, además de visitar los talleres de los artesanos de la zona. La rodocrosita es apreciada no sólo por su color sino por sus características para el tallado: aunque de origen volcánico, es relativamente blanda y se la puede pulir fácilmente. El yacimiento de Catamarca, el más largo del país con sus 26 kilómetros de galerías y 36 minas, se considera único en el mundo por sus vetas en bandas, mientras los demás que se conocen están formados por cristales de pequeño tamaño.

\subsection{Provincia de Mendoza}

- Paramillos. A 2.600 metros de altitud, en plena precordillera se encuentra una antigua ciudadela minera abandonada. Actualmente denominada la Ciudad Fantasmal de Paramillos, como un slogan para atraer a turistas y locales. Las primeras encomiendas españolas en Cuyo fueron establecidas en Uspallata, donde según documentos del Cabildo hacia 1660 había 319 bocas de minas registradas que podían compararse con las de Potosí (Perú) o Famatina (La Rioja). En ese desarrollo jugaron un rol importante los jesuitas, que en la zona se dedicaron a la producción minera y la fundición. En Paramillos, a unos 100 km de Mendoza, en el año 1620 instalaron una ciudadela para la extracción de plomo, plata, cobre, oro y zinc. Su mano de obra eran Huarpes y Araucanos, que vivieron y murieron en el lugar. Luego la zona fue explotada por españoles y desde el siglo XIX por alemanes y por los ingleses hasta 1982. Cada uno de ellos fue dejando rastros de su paso, como los corrales y la fundición de metal. De todo el conjunto resalta un edificio en cuyo interior hay un gran agujero, llamado pique Gobernador Elías Villanueva, que fue hecho en 1888 por el ingeniero y geólogo alemán Lave Lageman, tiene $90 \mathrm{~m}$. de profundidad y se usó para sacar agua y el mineral, que era llevado a la planta de procesamiento, donde se hacía la molienda y separación de los mismos por decantación. A la par, existen cuatro niveles de túneles donde se extraían los minerales de las vetas que iban abriendo en forma transversal y que tienen nombre de santos, acorde al día en que se abrían.

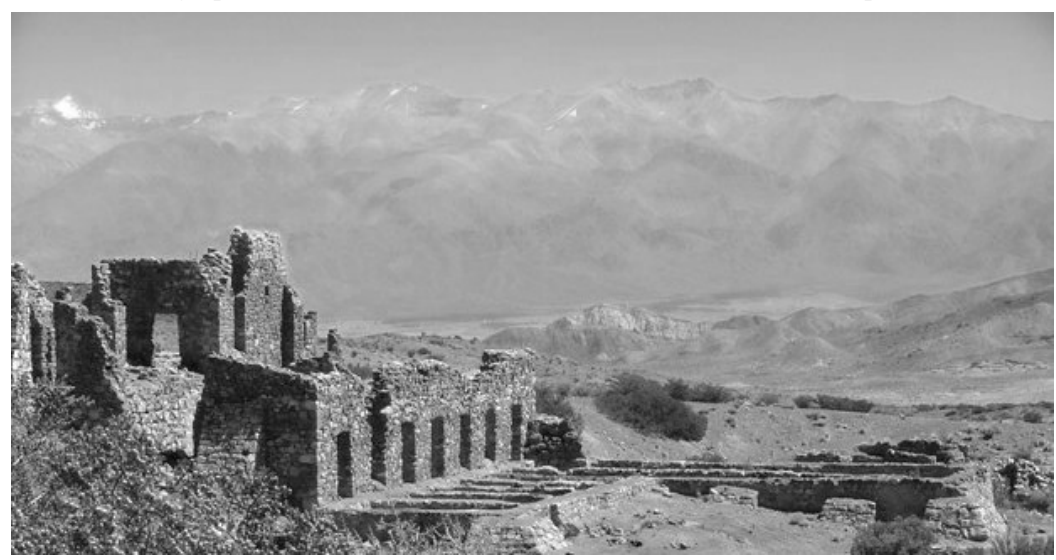

Figura 5. Vista del pueblo abandonado de Paramillos. Foto archivo personal.

\subsection{Provincia de La Pampa}

- La comarca de las salinas y los bosques pampeanos. Se pueden visitar y conocer los yacimientos de la Colorada Grande, La colorada chica y Callaqueo, la cual está ubicada en una profunda depresión, a menos de 40 mts., bajo el nivel del mar, convirtiéndola en la tercera más baja en el mundo. Estas áreas aportan el mineral bruto para la explotación de sal de mesa. Los recursos saliníferos de esta zona pueden se considerados, desde el punto de vista de la explotación, como una de los de mayor movimiento actual. El mineral más explotado es cloruro de sodio (sal), seguido por sulfato de sodio, yeso, bentonita, arenas, etc.

\subsection{Provincia de Córdoba}

\section{- Tanti/Los Túneles. Es un recorrido por un área que muestra una síntesis de 600 millones}

RAMOS SCHENCK, A.; FERNÁNDEZ ZAMBON, G.. La cultura del trabajo como recurso para la cultura del ocio: 
de años de historia de la Tierra. El itinerario comienza en el borde occidental de las Sierras Chicas (Tanti), continua por las Sierras Grandes, las Cumbres de Gaspar, Pampa de Pocho y Sierra de Guasapampa para culminar en los llanos occidentales ubicados en el extremo oeste de la provincia. Los puntos principales de esta alternativa minera son: la localidad de Tanti, el Cerro Blanco, que implica la visita a una mina de cuarzo y los atractivos geológicos identificados y demarcados como: Matadero, Los Gigantes, Kilómetro 792, El Contacto, Dos Ríos, Mirador Los Volcanes y Juan XXIII.

- Caverna Los Sauces. La Caverna, localizado en el poblado de La Falda constituye el segundo destino de turismo espeleológico del país. La caverna de carbonato de calcio tiene 800 metros de largo que muestran la evolución geológica del sector durante millones de años. En su interior corrieron ríos subterráneos que por una serie de movimientos geológicos disminuyeron su caudal hasta desaparecer. Esta caverna fue descubierta en la década de 1960 y en forma paulatina se conocieron sus laberintos. Posee numerosas bocas y desniveles que generan conexiones de aire permanente en su interior. Presenta diversas formaciones carboníticas y a diferencia de otras estructuras similares no cuenta con estalactitas ni estalagmitas. En su recorrido pueden observarse formaciones, muy similares a los corales de mar.

\subsection{Provincia de Río Negro}

- Mina de Sierra Grande. La localidad de Sierra Grande es una población que creció al lado de la mina de hierro más importante de Sudamérica, con 96 km de túneles y 480 metros de profundidad. En sus comienzos HiPaSAM (Hierro Patagónico de Sierra Grande Sociedad Anónima Minera), posteriormente HIPARSA (Hierro Patagónico Rionegrino Sociedad Anónima), bajo el gobierno provincial de Río Negro, fue cerrada por la Ley de Reforma del Estado en 1991, producto del proceso de desindustrialización y privatizaciones que vivió Argentina. En el 2005/2006 paso a manos de MCC Minera Sierra Grande S.A., que es una empresa minera controlada por capitales Chinos. En el periodo en que la mina estuvo bajo control provincial, algunos de los habitantes de la ciudad contribuyeron para convertir parte del lugar en uno de los primeros emprendimientos de turismo minero del país, llegando a recibir más de 22.000 turistas al año.
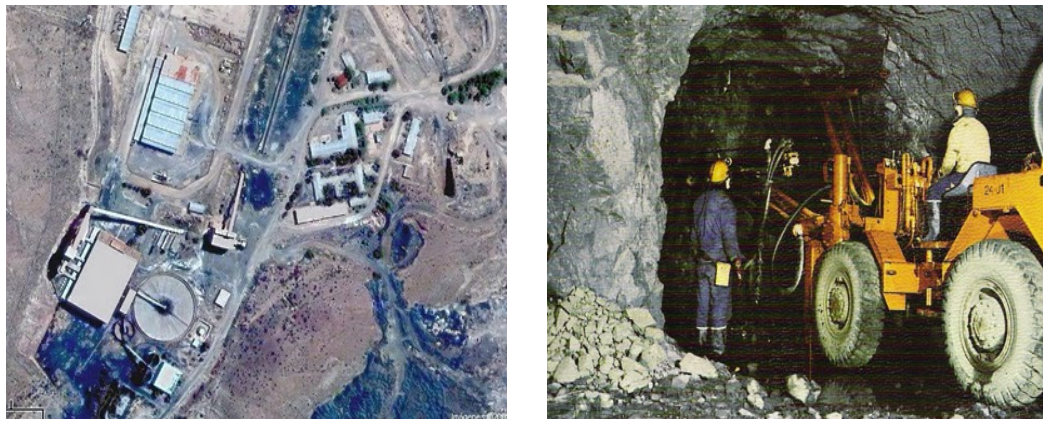

Figura 6. Vista instalaciones y maquinaria en Sierra Grande. Fotos: adnrionegro.com.ar y patagoniaenergetica.com

El circuito minero denominado Viaje al centro de la tierra, comprendía un recorrido total de $2 \mathrm{Km}$. por los túneles donde se extraía el hierro llegando hasta una profundidad de $60 \mathrm{mts}$. La actividad estaba organizada siguiendo los principios de la interpretación, ya que el guía comenzaba amenazando con hacer explotar un cartucho de dinamita, aclarando que se trata de una explosión de salva, y el estampido se va extinguiendo de a poco, como alejándose por las galerías. Después el guía proponía la experiencia opuesta, apagar las luces y guardar absoluto silencio en medio de la oscuridad. Esta experiencia permitía entender dos momentos que podían vivirse dentro de estos espacios. También el visitante realizaba el recorrido caminando sobre varios centímetros de agua. La explicación es que los mineros solían trabajar sobre pisos mojados para evitar que se levantara el polvillo que produce la silicosis (la enfermedad del minero). Dentro de la mina se podían realizar diferentes recorridos: por ejemplo por la chimenea de ventilación, que es un túnel vertical, era posible descender 15 metros practicando rappel. Otro túnel donde el techo esta derrumbado, deja un gigantesco agujero a cielo abierto, dando la sensación de estar en el fondo del cráter de un volcán. 
El guía, quien trabajó en la mina desde 1969, relataba cómo era el trabajo y los tipos de metal que se ven a simple vista: hierro, magnetita y pirita. Para terminar se realizaba un breve trecho por un río subterráneo, navegando en una balsa impulsada mediante pértigas y finalmente se regresaba por una galería donde permanecen inactivos martillos neumáticos y tractores. Actualmente el reinicio de las actividades mineras, a partir de capital de origen chino, eliminó las posibilidades de continuar y profundizar el desarrollo turístico.

\section{Reflexiones finales}

No es suficiente decir que proteger y conservar áreas y estructuras minero-industriales es fundamental por ser parte de nuestra identidad como sociedades e individuos, porque lamentablemente esto, en ocasiones, no es posible, por vivir en un mundo regido pura y exclusivamente por las normas del mercado libre, reduciendo todo simplemente a los beneficios económicos. Frente a esto, solo quedan dos caminos, enfrentarnos a este modelo en una lucha desigual, aunque sumamente noble, pero que en la mayoría de los casos termina siendo infructuosa, o intentar generar planes que permitan salvaguardar estos espacios, o por lo menos una parte de los mismos, incorporándolos a la economía a partir de las actividades recreativas, la cual permite utilizarlos sin la necesidad de realizar transformaciones significativas.

Esto no significa "rendirse" a los vaivenes del sistema económico, ni tampoco intenta ser una receta para acomodarse al modelo económico, sino más bien pretende ser una propuesta, compleja, para resguardar parte de los recursos culturales existentes relacionados a la actividad minera e industrial y al mismo tiempo generar ingresos para innumerables comunidades que han quedado fuera de las ventajas que puede implicar la economía global.

En esta línea, el turismo y las actividades recreativas en general, pueden ser un elemento que permita la dinamización y la búsqueda de rentabilidad de las infraestructuras y elementos asociados a la industria y a la minera. Para los proyectos turístico-recreativos esto significa un enorme desafío no solo por el reto que implica su puesta en valor sino también porque se convierten en guardianes, dependiendo de estos el resguardo y la permanencia, el respeto y cuidado de bienes que pertenecen a tres momentos que se conjugan en estos recursos culturales, el pasado, el presente y el futuro traducido este último, en la concepción de un legado.

Finalmente considerando el análisis de los recursos culturales vinculados a la minería e industria en Argentina, podemos decir que cuenta con un patrimonio extraordinariamente diverso, que en muchos casos es capaz de generar productos turísticos con poder de atracción nacional, al menos, e incluso internacional, en otros casos. Pero es necesario que el Estado actúe, planificando y elaborando planes de gestión de los recursos, para que el sector privado lleve adelante los emprendimientos.

En definitiva el valor de estos proyectos tiene que ver con una labor de mostrar a la sociedad, por una parte, un tipo de actividad que ha sido y es muy importante como suministradora de materias primas necesarias para nuestra forma y calidad de vida y, por otra, los yacimientos minerales relacionados, incluso el significado de agotamiento de un recurso natural. Por esto es sumamente importante relevar los pasivos ambientales de la Argentina, establecer condiciones de estado y proyectarlos en escenarios futuros donde sean las mismas comunidades las que establezcan como activar lo que hace a su patrimonio... para legarlo enriquecido a las generaciones futuras.

\section{Referencias}

AMADASI, Enrique (comp.). Política Turística Argentina, Bases para su reformulación. Buenos Aires: LADEVI Ediciones, 1999.

BAÑEZ, Maite; ZABALA, Mar.. El patrimonio industrial vasco. Consejo Vasco de Cultura, 2003.

CANDELA, P.; CASTILLO, J.; LÓPEZ GARCÍA, M. (2001). "El patrimonio industrial y la memoria del trabajo en la Comunidad de Madrid". En dossier monográfico del Bulletí d'Arqueología Industrial i de Museus de Ciència i Tècnica. pp. 1-9. 
CAPEL, Horacio. El Turismo Industrial y el Patrimonio Histórico de la Electricidad. Sevilla: Instituto Andaluz del Patrimonio Histórico, 1996.

CARVAJAL, D.; GONZÁLEZ, A. Patrimonio minero y cierre de minas. España: Universidad de Huelva, 2002.

LECOURS, Jacques. L'Insertion du Patrimoine Industriel Dans L'Infraestructure Touristique: problemes d'attrait et d'authenticité. Quebec [Canadá]: Université du Quebec, 1990.

LLURDES I COIT, Joan. El Turismo de Patrimonio Industrial y Minero. Una experiencia de turismo interior explotada en el Estado español. Barcelona: Universidad Autónoma de Barcelona, Departamento de Geografía, 1995.

MARTÍN DE LA ROSA, Beatriz. Nuevos turistas en busca de un Nuevo producto. El patrimonio cultural. Revista Pasos. Vol 1 № 2. http://www.pasosonline.org .

Pardo Abad, C.. La reutilización del patrimonio industrial como recurso turístico. Aproximación geográfica al turismo industrial. En Treballs de la Societat Catalana de Geografía. № 57, pp. 7-34, 2004.

PAZ, Carlos; VISVEQUI, Raúl. Turismo Industrial y Patrimonio Cultural en Olavarría. El pasado de la industria minera como potencial turístico. GIAAI. NURES. Facultad de Ciencias Sociales. UNCPBA, 2001.

PUCHE, O.; MAZADIEGO, L. F.. Conservación del patrimonio minero metalúrgico español: actuaciones recientes y propuestas. Tecnoambiente. 69. pp. 39-43, 1997.

RODRÍGUEZ ACHUTEGUI, Maribel. El turista cultural y las ciudades históricas. En Boletín del IAPH. Andalucía, 2002.

SANTANA, Agustín. Editorial. Revista Pasos. №1, 2003. Disponible en http://www.pasosonline.org . 